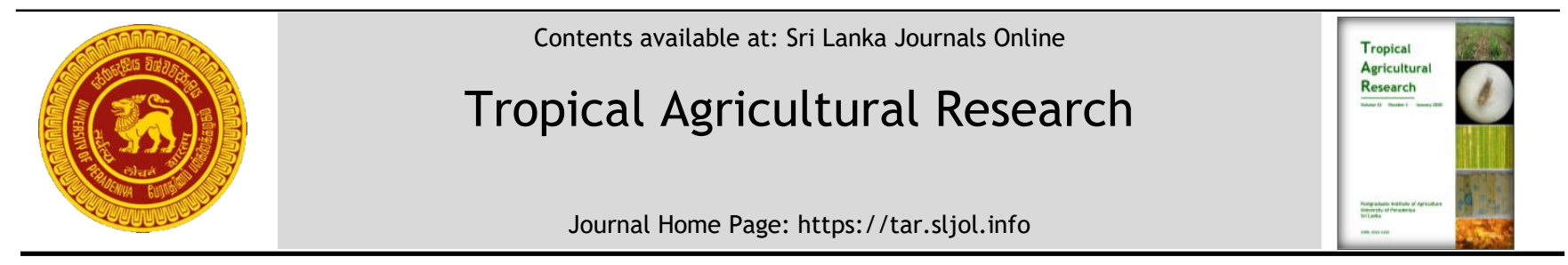

\title{
Response of Tree Community Composition, Plant Diversity and Aboveground Tree Biomass in Tropical Rainforests of Sri Lanka to Variation in Altitude
}

\author{
H. K. N. Sanjeewani ${ }^{1,8^{*}}$, D. P. Samarasinghe ${ }^{2}$, H. D. Jayasinghe ${ }^{3}$, P. H. Gardiyawasam ${ }^{7}$, W. M. P. S. B. \\ Wahala4, W. M. G. A. S. T. B. Wijetunga ${ }^{5}$, K. D. B. Ukuwela 5 , P. Gomes ${ }^{6}$ and W. A. J. M. De Costa ${ }^{7}$ \\ ${ }_{1}^{1}$ Postgraduate Institute of Agriculture, University of Peradeniya, Sri Lanka; ${ }^{2}$ Postgraduate Institute of Archaeology, \\ University of Kelaniya, Sri Lanka; ${ }^{3}$ National Institute of Fundamental Studies, Kandy, Sri Lanka; ${ }^{4}$ Department of Tourism \\ Management, Faculty of Management Studies, Sabaragamuwa University of Sri Lanka; ${ }^{5}$ Department of Biological \\ Science, Faculty of Applied Sciences, Rajarata University of Sri Lanka, Sri Lanka; ${ }^{6}$ Forest Department Sri Lanka \\ ${ }^{7}$ Department of Crop Science, Faculty of Agriculture, University of Peradeniya, Sri Lanka; ${ }^{8}$ Department of Biological \\ Science, Faculty of Applied Science, Vavuniya Campus of the University of Jaffna, Sri Lanka
}

\section{ARTICLE INFO}

\section{Article history:}

Received: 21 August 2019

Accepted: 03 November 2019

Available online: 01 December 2019

\section{Keywords:}

Aboveground biomass

Altitudinal gradient

Floristic composition

Tropical rainforests

Vegetation diversity

\section{Citation:}

Sanjeewani, H. K. N., Samarasinghe, D. P., Jayasinghe, H. D., Gardiyawasam, P. H., Wahala, W. M. P. S. B., Wijetunga, W. M. G. A. S. T. B., Ukuwela, K. D. B., Gomes, P. and De Costa, W. A. J. M. (2020) Response of Tree Community Composition, Plant Diversity and Aboveground Tree Biomass in Tropical Rainforests of Sri Lanka to Variation in Altitude. Tropical Agricultural Research, 31(1): 87-101. DOI: http://doi.org/10.4038/tar.v31i1.8346 Sanjeewani, H. K. N. (ID https://orcid.org/0000-0002-7188-9658

*Corresponding author: nimalka.sanjeewani@gmail.com

\section{ABSTRACT}

Tropical rain forests (TRFs) are a major carbon sink and play an important role in regulating the global climate. Floristic composition, structure and carbon storage in biomass of TRFs could vary substantially with climatic and edaphic factors. Altitudinal transects represent an excellent setting for investigating the responses of TRFs to environmental change. Objectives of this study were to determine the variation patterns and possible inter-relationships between plant community composition, diversity and aboveground biomass (AGB) in TRFs across an altitudinal gradient from $134 \mathrm{~m}$ to $1,667 \mathrm{~m}$ above sea level in Sri Lanka. Five permanent sampling plots of 1 ha each, consisting of four plots in lowland rainforests in Kanneliya and PitadeniyaSinharaja Forest Reserves and one plot in the tropical montane forest in Rilagala, were established. Trees with $\mathrm{DBH} \geq 10 \mathrm{~cm}$ were measured and taxonomically identified. A total of 3,781 trees, belonging to 191 species from 106 genera and 53 families were recorded, with a total basal area of $203.68 \mathrm{~m}^{2}$. Floristic composition of sampling plots showed substantial variation with altitude. Tree density and numbers of species, genera and families and plant diversity indices (i.e. Shannon-Wiener and Simpson's Indices, evenness and richness of tree species) showed negative curvilinear declines with increasing altitude. Mean DBH, tree basal area and AGB increased from low- (348 kg ha-1) to midaltitudes (762 $\mathrm{kg} \mathrm{ha}^{-1}$ ) and decreased from mid- to highaltitudes $(70 \mathrm{~kg} \mathrm{ha-1})$, thus showing second-order polynomial relationships with altitude. Similar trends were shown between AGB and tree species number and diversity indices, thus indicating that $\mathrm{AGB}$ is maximum at intermediate vegetation diversity. 


\section{INTRODUCTION}

Tropical rain forests (TRFs) are a key component of the global carbon cycle (Detwiler and Hal, 1988; Phillips et al., 1998; Brienen et al., 2015) while being one of the most diverse ecosystems in the world (Gallery, 2014). They provide habitats for many life forms such as mammals, birds, insects and plants. Even though TRFs have a broadly similar physiognomy and vertical structure, they may differ in spiecies composition due to variations in climate, geology, soil and human intervention (Gallery, 2014). Furthermore, environmental heterogeneity and dispersal limitations could influence species composition in TRFs. Locally-dominant tree species can be found in the primary TRFs throughout the tropical region with the family Dipterocarpaceae being dominant in the Asian tropics while Caesalpiniaceae dominating African and neotropical TRFs (Gallery, 2014).

Ecosystems located at different altitudes are exposed to substantial variations in their above and below-ground environment (Körner, 2007). For example, atmospheric temperature and pressure decrease with increasing altitude in a predictable manner. Less predictably, climatic factors such as precipitation vary across altitudes when variations in atmospheric pressure and temperature combine with other factors such as topography and wind patterns. Decreasing temperatures along altitudinal gradients in combination with precipitation variations introduce heterogeneity in edaphic factors by influencing biogeochemical processes such as rock and soil weathering and decomposition of plant litter and soil organic matter. Therefore, investigation of the biogeography and diversity of TRFs across altitudinal transects provide essential insights into how this crucial ecosystem may be responding to environmental change, including anthropogenic climate change (Malhi et al., 2010). In this regard, the lowland rainforests and montane forests of Sri Lanka, which span in an altitudinal range from $c a .100 \mathrm{~m}$ to 2,300 $\mathrm{m}$ above sea level (asl), represent an excellent landscape for an in-depth investigation into ecosystem processes in TRFs.

Variation of community structure, biogeography, vegetation diversity, standing biomass and net primary productivity in TRFs across altitudinal gradients have been investigated in many parts of the world, including South-East Asia (Aiba and Kitayama, 1999; Kitayama and Aiba, 2002; Culmsee et al., 2010; Slik et al., 2010), South America (Girardin et al., 2010; Moser et al., 2011; Malhi et al., 2017), Central America (Lieberman et al,. 1996), Pacific Islands (Raich et al., 1997) and Africa (Lovett et al., 2006; Marshall et al., 2012). In addition, there have been a few conceptual analyses to model the vegetation responses to environmental variations across altitudinal gradients (Givnish, 1999; Wang et al., 2003). A majority of the studies conducted so far point towards increased tree density and decreasing trends in tree stature (as measured primarily by height and canopy size), vegetation diversity, aboveground biomass and net primary productivity with increasing altitude. However, there are exceptions such as the reported maximum tree stature and vegetation diversity at midaltitudes (Lieberman et al., 1996) and increased basal area at high altitudes (Lieberman et al., 1996). Furthermore, while a majority of studies has reported a continuous decline in aboveground biomass (AGB) with altitude, Marshall et al. (2012) observed an increase in AGB up to a mid-altitude and a subsequent decline. On the other hand, Culmsee et al. (2010) reported almost constant aboveground biomass across mid- to high altitudes. Changes in vegetation composition and phylogenetic diversity, in terms of species, genera and families, with increasing altitude have been reported in all 
studies that have investigated this aspect (e.g. Lieberman et al., 1996; Vázquez and Givnish, 1998; Culmsee et al., 2010; Slik et al., 2010).

Even though there are common trends in the variation of certain floristic and biogeographical characteristics with altitude, many region-specific factors could modify the magnitude of such variations. For example, Raich et al. (1997) and Aiba and Kitayama (1999) reported such modified altitudinal responses caused by variations in soil properties. Furthermore, region-specific variations in phylogenetic diversity and plant traits such as wood specific gravity could have significant influences on tree stature, standing biomass and net primary productivity across altitudes (Culmsee et al., 2010). This warrants region-specific investigations such as the present work undertaken in the TRFs in Sri Lanka along an altitudinal gradient.

Tropical rainforests in Sri Lanka are highly important due to their high endemicity in flora and fauna. For example, the Sinharaja Man and Biosphere Reserve (MBR) is considered as one of the global biodiversity hotspots (Gunawardene et al., 2007). Tropical rainforests are located in the south-western part of Sri Lanka and their locations range from sea level to more than $2,000 \mathrm{~m}$ above sea level (asl). Forests up to $c a$. 1,000 m asl can be considered as lowland rain forests while those above $c a$. 1,000 asl are categorized as tropical montane forests. These forests are a key primary production source and the main protection home of watersheds while sustaining the natural beauty of the landscape. Accordingly, the present study was conducted with the primary objective of detecting variation patterns in the plant community composition and diversity in a series of permanent sampling plots in TRFs established across an altitudinal gradient ranging from 134 to $1667 \mathrm{~m}$ asl. A secondary objective was to determine the variation of standing aboveground biomass (AGB) with altitude and explore its possible relationships with plant diversity. This is part of a wider long-term study to quantify the net primary productivity of TRFs in Sri Lanka and its variation with environmental change.

\section{MATERIALS AND METHODS}

\section{Study sites and field work}

This study was focused on five permanent sampling plots of 1 ha $(100 m \times 100 m)$ each located along an altitudinal gradient from 134 to $1,667 \mathrm{~m}$ asl (Figure 1). Two plots each were located in the Kanneliya Forest Reserve and Pitadeniya in the Sinharaja MAB Reserve, which has been declared as a world heritage site. One plot was located in the Rilagala Forest, which was accessed via Queensberry Tea Estate along the NawalapitiyaTalawakelle road. Long-term averages of essential climatic variables of the locations of sampling plots are given in Table 1.

Table 1: Long-term averages of climatic variables in the permanent sampling plots

\begin{tabular}{|c|c|c|c|c|c|c|c|c|}
\hline Location & $\begin{array}{l}\text { Altitude } \\
\text { (m) }\end{array}$ & $\begin{array}{l}+T_{\text {min }} \\
\left({ }^{\circ} \mathrm{C}\right)\end{array}$ & $\begin{array}{l}T_{\max } \\
\left({ }^{\circ} \mathrm{C}\right)\end{array}$ & $\begin{array}{l}T_{\text {mean }} \\
\left({ }^{\circ} \mathrm{C}\right)\end{array}$ & $\begin{array}{l}\text { ‡Rainfall } \\
\left(\mathrm{mm} \mathrm{y}^{-1}\right)\end{array}$ & $\begin{array}{l}\text { Radiation } \\
\left(\mathrm{kJ} \mathrm{m}^{-2} \mathrm{~d}^{-1}\right)\end{array}$ & $\begin{array}{c}\text { VP } \\
(\mathrm{kPa})\end{array}$ & $\begin{array}{c}W \\
\left(\mathrm{~m} \mathrm{~s}^{-1}\right)\end{array}$ \\
\hline KDN1 & 134 & 23.5 & 29.8 & 26.3 & 3656 & 18832.8 & 2.8 & 2.3 \\
\hline KDN2 & 152 & 22.8 & 29.3 & 26.3 & 3788 & 18945.3 & 2.8 & 2.3 \\
\hline PTD1 & 606 & 20.4 & 26.9 & 23.7 & 3901 & 18330.3 & 2.0 & 1.9 \\
\hline PTD2 & 509 & 21.1 & 27.9 & 24.3 & 3877 & 18495.8 & 2.2 & 1.9 \\
\hline RLG & 1667 & 14.9 & 22.1 & 18.6 & 2569 & 17680.1 & 1.8 & 1.8 \\
\hline
\end{tabular}

${ } \mathrm{T}_{\min }$ - Mean annual minimum temperature; $\mathrm{T}_{\max }$ - Mean annual maximum temperature; $\mathrm{T}_{\text {mean }}-\mathrm{Mean}$ annual mean temperature; $\neq$ Rainfall - Mean annual total rainfall; Radiation - Mean daily incident solar radiation; VP - Mean atmospheric vapour pressure; W -Mean wind speed (Fick \& Hijmans, 2017) 
Plots were enumerated during January - June 2019. The diameter at breast height $($ Height $=$ $1.3 \mathrm{~m}$ ) of all woody stems $\geq 10 \mathrm{~cm}$ was measured and tagged. The standardized census protocols used by Phillips et al. (1998) and Baker et al. (2004) were used (http://www.rainfor.org/en/manuals).Taxon omic identification was made using standard keys.

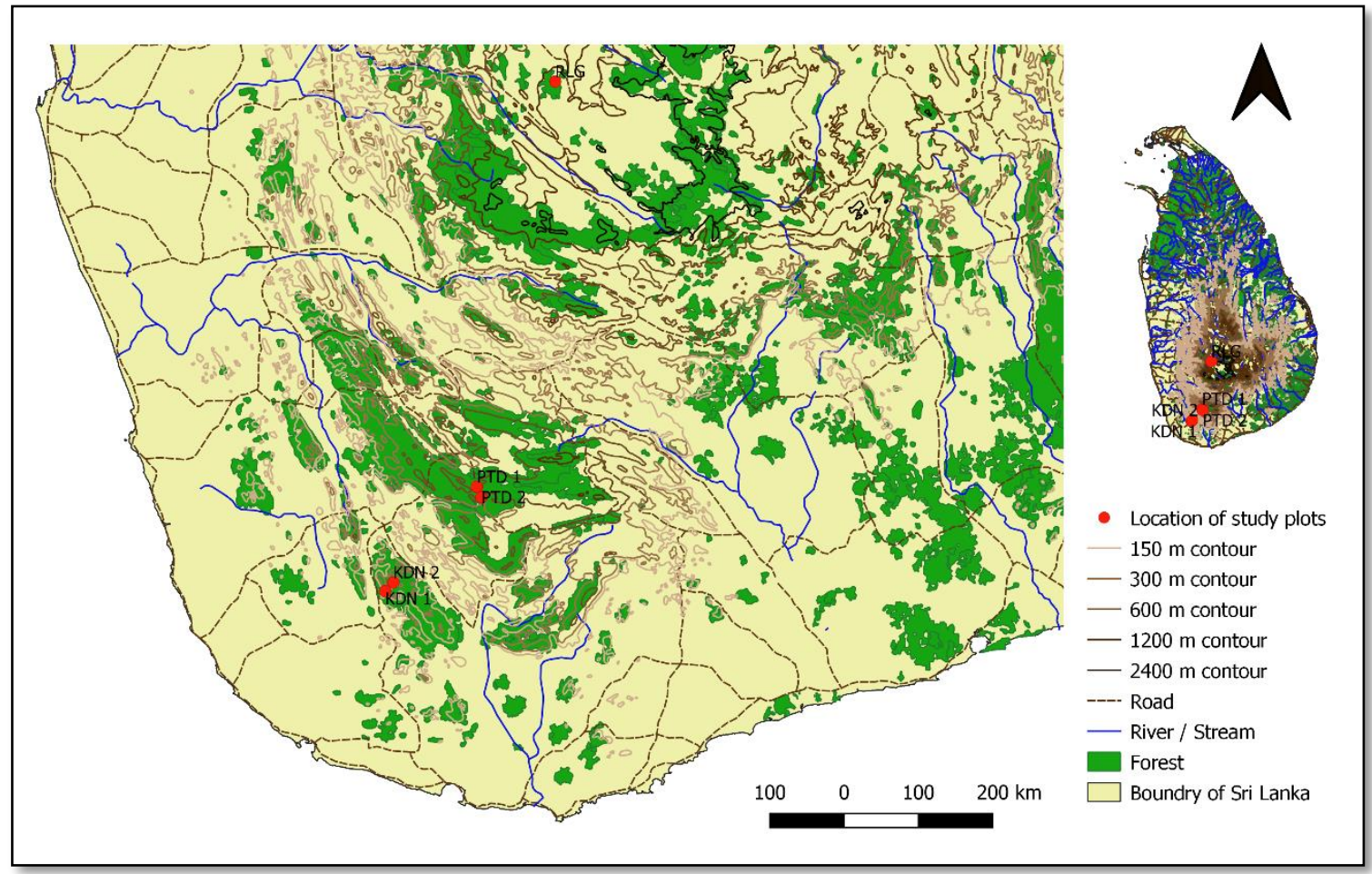

Figure 1: Permanent sampling plots of the present study located at different altitudes in tropical rain forests of Sri Lanka. Kanneliya Plot 1 (KDN1-134 m asl), Kanneliya Plot 2 (KDN2-152 m), Sinharaja-Pitadeniya Plot 1 (PTD1-606 m), Sinharaja-Pitadeniya Plot 2 (PTD2-509 m) and Rilagala Plot (RLG-1667 m).

\section{Calculations}

Basal area was calculated using the equation for the area of a circle as,

$$
\text { Basal Area } \left.=\pi(D B H / 2)^{2} \quad \text { (eq. } 1\right)
$$

The allometric equation developed by Chave et al., (2005) for moist forest stands was used to convert DBH to aboveground biomass (AGB) in each individual tree:

$A G B=\rho \times \exp [-1.499+2.148 \ln (D)+$ $\left.0.207(\ln (D))^{2}-0.0281(\ln (D))^{3}\right]$ (eq. 2)

Where, $\rho$ is wood density (i.e. dry biomass of wood per unit of fresh wood volume, $\mathrm{g} \mathrm{cm}^{-3}$ ), D is diameter at $1.3 \mathrm{~m}(\mathrm{~cm})$. This equation was selected based on the long-term evaporation and annual rainfall data in regions where the permanent sampling plots are located. Species-specific $\rho$ values were obtained from global databases (Reyes et al., 1992; Chave et al., 2009; Zanne et al., 2009; Harja et al., 2019). When $\rho$ for a particular species was not available in the database, an available value for the next higher taxonomic class (i.e. the genus or the family) was used.

In each permanent sampling plot (PSP), the following plant diversity indices were calculated:

Shannon-Wiener index $\left(\mathrm{H}^{\prime}\right)$ :

$$
\left(H^{\prime}\right)=-\sum\left[\left(\frac{n i}{N}\right) \times \ln \left(\frac{n i}{N}\right)\right]
$$

Evenness:

$$
(J)=\frac{1}{H^{\prime}}
$$


Simpson's Index:

$$
D=\frac{\sum n(n-1)}{N(N-1)}
$$

Species richness $(\mathrm{d})$ :

$$
d=s / \sqrt{ } N
$$

Where, $\mathrm{n}_{\mathrm{i}}$ is the number of individuals of each species (the $i^{\text {th }}$ species), $\mathrm{N}$ the total number of individuals in each PSP and ln the natural logarithms of $n$ and $N$, $s$ is number of different species represented. Species dominance was calculated by using Simpson Index (D).

\section{Data analysis}

Normality of data was tested by the ShapiroWilk's Normality Test. Linear or non-linear response patterns to variation in altitude were initially detected with scatter plots. Simple linear regression and polynomial regression were used to determine linear responses and some non-linear responses respectively. Negative curvilinear responses were determined by simple linear regression with the reciprocal of altitude. Adjusted $R^{2}$ and the probability of the $F$-statistic being due to random variation ( $p$-value) were used to determine the most appropriate regression model. Data were analysed by using RStudio (ver.1.2.1335) and regression models were tested by using Ime4 package in R (Bates et al., 2017) and SAS Studio University Edition. Species richness, evenness and dominance were calculated by using vegan (Oksanen et al., 2019) and BiodiversityR packages (Kindt and Coe, 2005).

\section{RESULTS AND DISCUSSION}

A total of 3,781 trees having DBH $\geq 10 \mathrm{~cm}$ with a total basal area of $203.68 \mathrm{~m}^{2}$ were censused from the five PSPs. The number of trees per ha was highest at the lowest elevation in KDN and declined with increasing altitude in PTD and RLG (Figure 2.a). A negative curvilinear relationship showed a highly significant fit to this declining pattern. This observation contrasted with the findings of Weaver and Murphy (1990), Aiba and Kitayama (1999) and Leuschner and Moser (2008) who reported increased stem density with increasing altitude. Tree basal area ha-1 increased with increasing altitude up to a maximum at $636 \mathrm{~m}$ asl and declined thereafter (Figure 2.b), thus fitting a significant secondorder polynomial function. A similar trend in the basal area was observed by Gould et al. (2006). In contrast, Lieberman et al. (1996) did not observe a consistent trend in tree basal area from 100 to $1,500 \mathrm{~m}$ asl, followed by an appreciable increase up to 2,600 m asl. Across all sampling plots, trees belonging to 191 species were recorded from 106 genera and 53 families. The numbers of tree species, genera and families in the sampling plots showed negative curvilinear declining trends with increasing altitude (Figures 2.c-e). This is supported by a wide body of observations in TRFs across altitudinal gradients (Aiba and Kitayama, 1999; Givnish, 1999 and references therein). The rates of reduction were greater at the lower altitudinal ranges (i.e. approximately from 100 to $600 \mathrm{~m}$ ) than at higher ranges $(600-1,800 \mathrm{~m})$, where the reductions were marginal. The precision of these declining trends, as quantified by the adjusted $R^{2}$ and $p$-value, was highest at the tree species level and decreased with expanding taxonomic grouping (i.e. genus and family levels).

Most common plant species recorded in KDN1 was Alstonia macrophylla $(11.67 \%$ of the total tree number) whereas Syzygium grande $(9.76 \%)$ was the most abundant in KDN2. Shorea affinis (15.78\%), Mesua thwaitesii (17.49\%) and Palaquium rubiginosum $(20.71 \%)$ made the highest contribution to the tree population at PTD1, PTD2 and RLG respectively. The most frequent genus recorded in KDN1 was Alstonia (11.67\%) whereas Shorea was the most abundant in KDN2 (26.82\%) and PTD1 (30.24\%) respectively. The corresponding genera making the highest contributions at PTD2 and 
RLG were Mesua (25.58\%) and Palaquium (20.71\%) respectively. Family Apocynaceae (11.67\%) to which Alstonia macrophylla belongs was the family making the highest contribution to the tree community at KDN1. In contrast, family Dipterocarpaceae, with 16 species (29.94\%) and 8 species (32.89\%) contributed the most to KDN2 and PTD1 respectively. Even though, there were ten tree species belonging to Dipterocarpaceae in PTD2, Calophyllaceae (25.54\%), which contributed two tree species, was the most common plant family. Although Sapotaceae $(20.71 \%)$ was the most abundant family in RLG, it contributed only Palaquium rubiginosum to the tree community. Similar changes in community composition, distribution of tree families and their dominance patterns along altitudinal gradients have been reported by Lieberman et al. (1996), Vázquez G and Givnish (1998), Aiba and Kitayama (1999) and Culmsee et al. (2010).
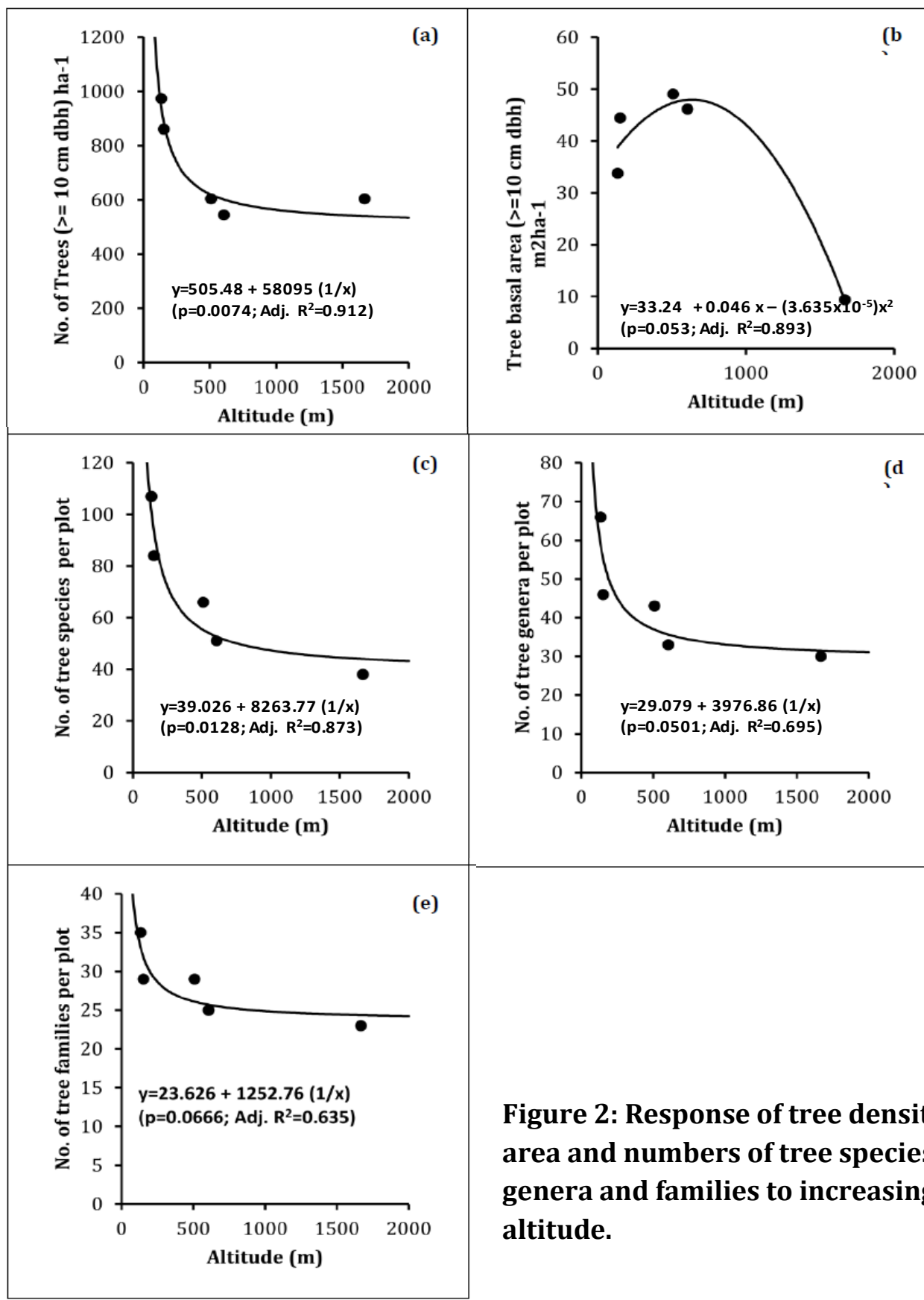

Figure 2: Response of tree density, basal area and numbers of tree species, genera and families to increasing altitude. 


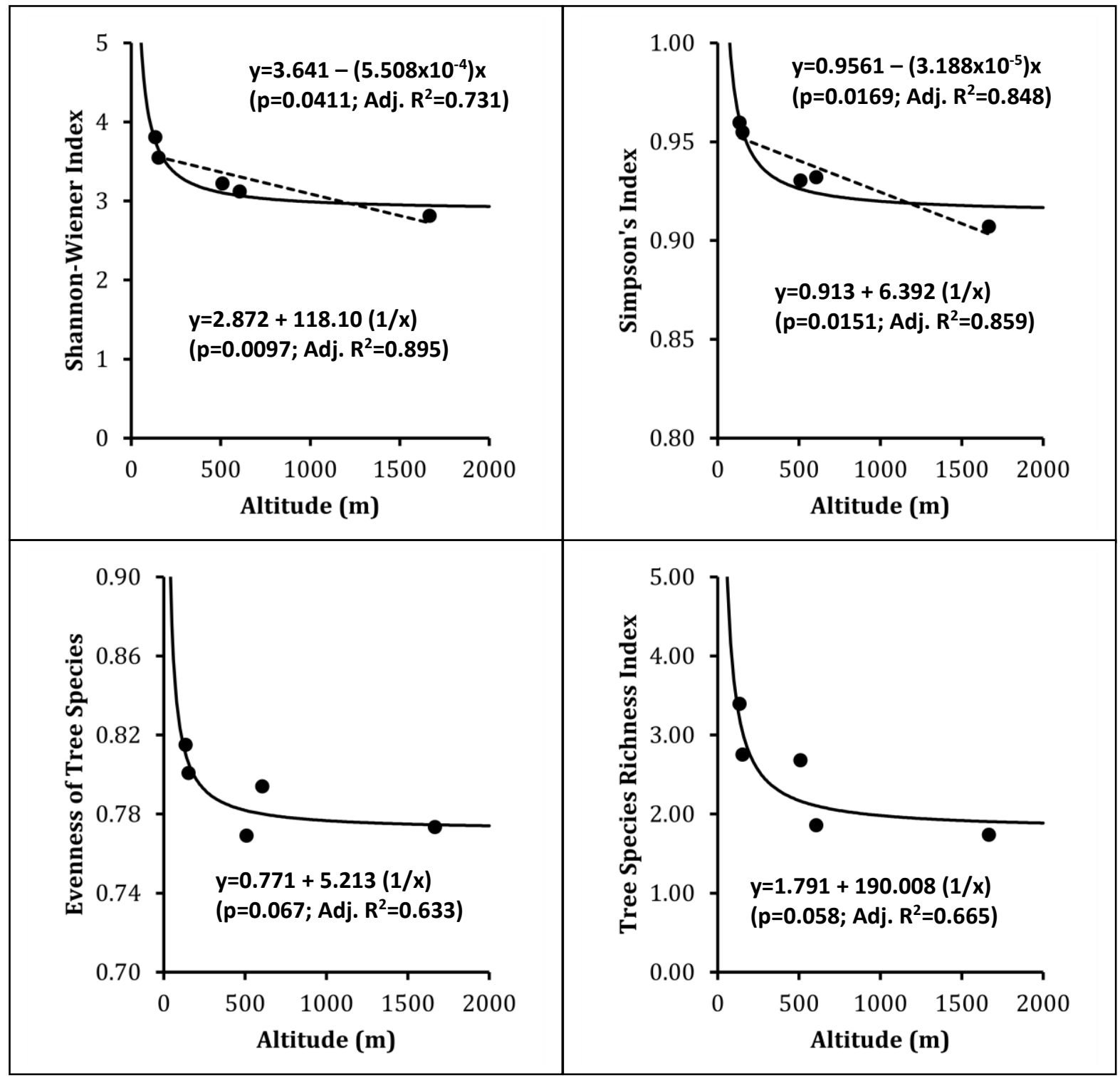

Figure 3: Response of indices of plant diversity, evenness and species richness index to increasing altitude.

Trees with less than $20 \mathrm{~cm}$ DBH formed the most considerable fraction of the total tree population in all sampling plots (Figure 4). This agreed with the findings of Aiba and Kitayama (1999) and Culmsee et al. (2010). At lower and mid-altitudes, their contributions were between $61-68 \%$ whereas, at higher altitude, they contributed nearly $96 \%$. Percentage contribution from the $20-40 \mathrm{~cm}$ DBH class was greater in the two plots at KDN (28-30\%) than in the two plots at PTD (24\%) and the plot at RLG (4\%). Notably, there were no trees having greater than $80 \mathrm{~cm}$ DBH at KDN1 and RLG. The KDN1 plot differed from the rest of the plots at lower- (KDN2) and midaltitudes (PTD1 and PTD2) in having relatively lower percentages of trees within the 40-60 $\mathrm{cm}$ and 60-80 $\mathrm{cm}$ DBH classes. The sum of DBH ha-1 showed a strong negative linear relationship with increasing altitude (Figure 5.a). On the other hand, the total aboveground biomass (AGB) per ha increased with increasing altitude up to an optimum of $741 \mathrm{~m}$ asl and declining thereafter (Figure 5.d), thus 
showing a second-order polynomial relationship. This agreed with the trend observed by Gould et al. (2006). However, it contrasted with the findings of Aiba and Kitayama (1999) and Kitayamat and Aiba (2002) who observed a linear decline of AGB and with Culmsee et al. (2010) who did not observe a significant trend. Second-order polynomial relationships were shown for the mean and range of DBH (Figures 5.b \& c.), with the respective maxima at 744 and $861 \mathrm{~m}$ asl. In contrast, Lieberman et al. (1996) observed approximately constant mean DBH from 100 to $1500 \mathrm{~m}$ asl followed by a slight increase up to $2600 \mathrm{~m}$ asl.
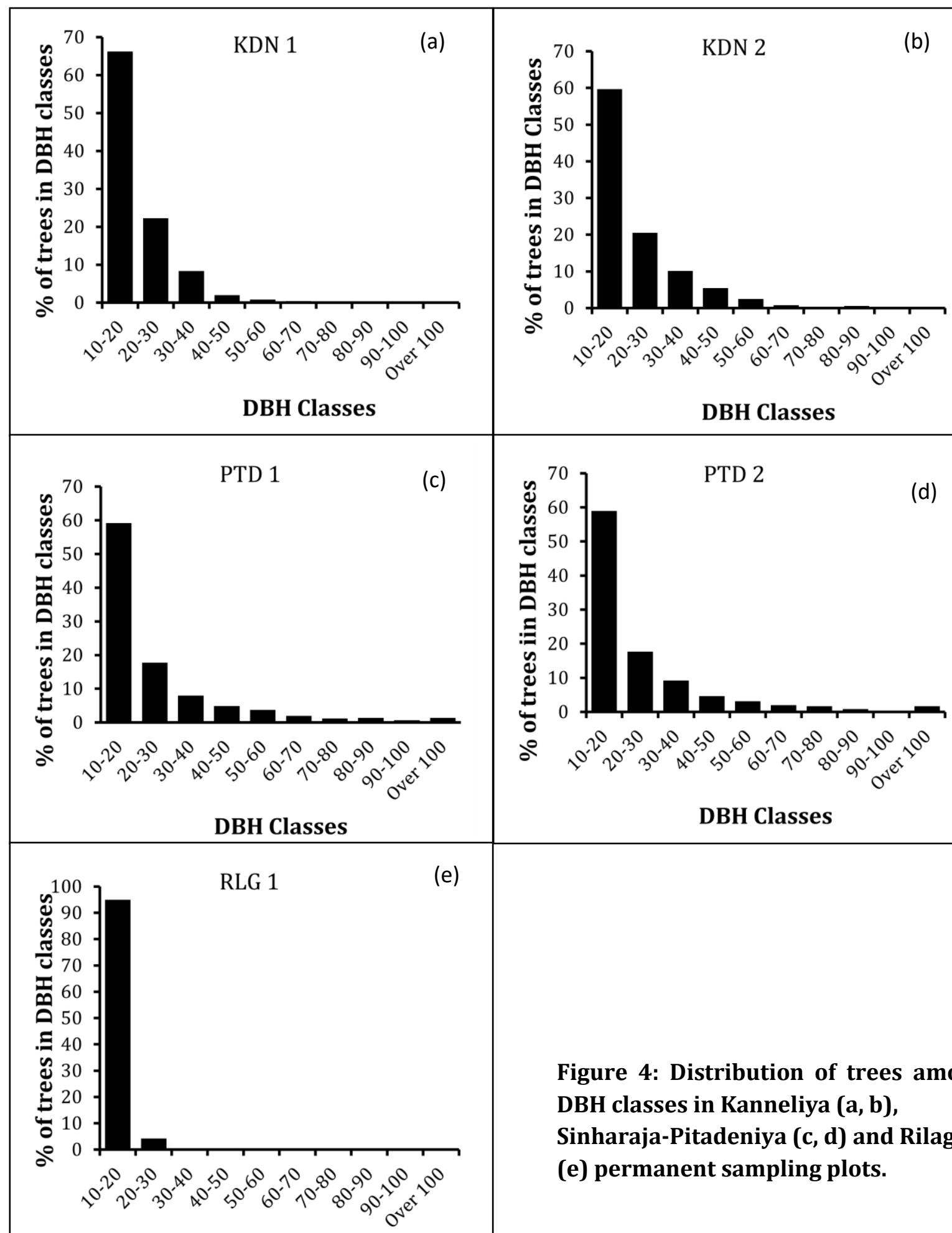

DBH Classes

70 PTD 2

Figure 4: Distribution of trees among DBH classes in Kanneliya (a, b), Sinharaja-Pitadeniya (c, d) and Rilagala (e) permanent sampling plots. 


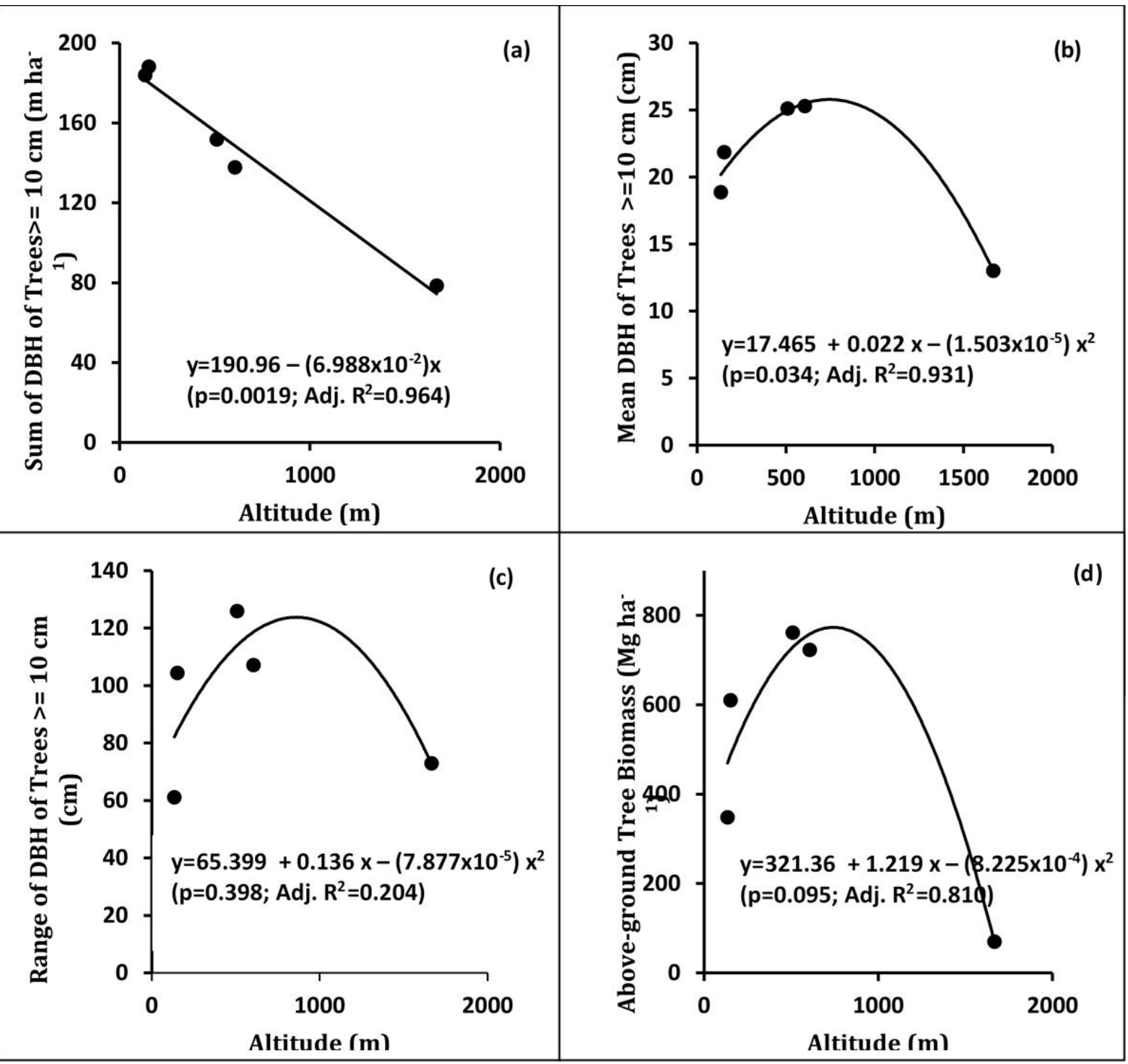

Figure 5: Response of total DBH (a), mean DBH (b), range of DBH (c) and above-ground biomass (d) of trees ( $\geq 10 \mathrm{~cm} \mathrm{DBH)}$ to increasing altitude.

Contributions to the total AGB from the respective DBH classes differed at different altitudes (Figure 6). At the lowest altitude in $\mathrm{KDN}$, trees in DBH classes from 20 to $40 \mathrm{~cm}$ and from 40 to $60 \mathrm{~cm}$ contributed most to the total AGB in both absolute (Figure 6.a) and percentage (Figure 6.b) terms. In contrast, at the mid-altitude in PTD, the highest contribution was from large trees with DBH > $100 \mathrm{~cm}$. At the same time, other diameter classes from 20 to $100 \mathrm{~cm}$ also contributed substantially and approximately uniformly (ca. 100-150 $\mathrm{Mg} \mathrm{ha}^{-1}$ and 20\%) to the total AGB at PTD, with the smallest DBH class (10$20 \mathrm{~cm}$ ) making the lowest contribution. On the other hand, at the higher altitude in RLG, the smallest DBH class made the highest contribution. This finding contrasted with the observation of Culmsee et al. (2010) on tropical montane rainforests in Sulawesi, Indonesia, where the larger trees $(30-100 \mathrm{~cm}$ $\mathrm{DBH})$ contributed substantially to the total AGB. 


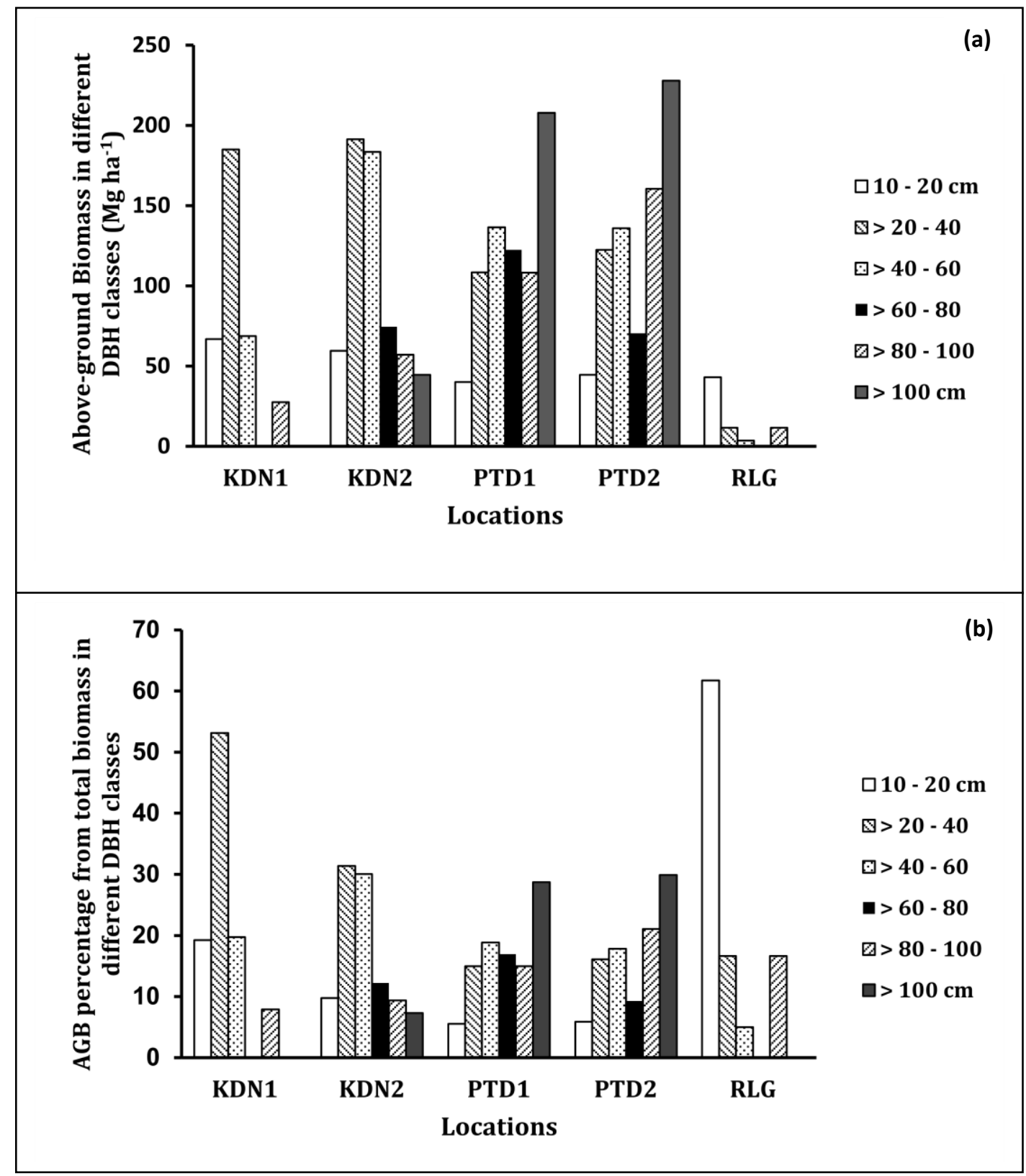

Figure 6: Distribution of total above ground biomass (AGB) of trees among DBH classes in sampling plots:(a) AGB in DBH classes; (b) \% of total AGB in DBH classes. KDN, PTD and RLG refer to Kanneliya, Sinharaja-Pitadeniya and Rilagala sampling sites.

Total aboveground biomass showed a strong positive linear relationship with tree basal area (Figure 7.a) and significant $(p<0.05$, Adj. $R^{2}>0.9$ ) second-order polynomial relationships with tree diversity measured in terms of the Shannon-Wiener (Figure 7.b) and Simpson's (Figure 7.c) indices. A similar, but less precise ( $p=0.199, A d j . R^{2}=0.6$ ), polynomial relationship was present between AGB and the number of tree species (Figure 7.d).

These polynomial relationships, which showed parallel reductions in species number, diversity and AGB from the mid-altitude at PTD to the higher altitude at RLG, were in partial agreement with similar reductions observed by Lieberman et al. (1996) and Aiba and Kitayama (1999). On the other hand, the 
reduction in AGB at KDN despite increased species number and tree diversity is contrary to the observed trend. However, it is notable that in an extensive global-scale study of the relationship between tree species diversity and biomass carbon storage in tropical forests, Sullivan et al. (2017) did not find a significant relationship among 360 sampling plots of 1 ha each. On the other hand, a weak positive relationship was found among 0.04 ha subplots within 1 ha plots, thus suggesting that the diversity-biomass relationship is dependent on the spatial scale considered.

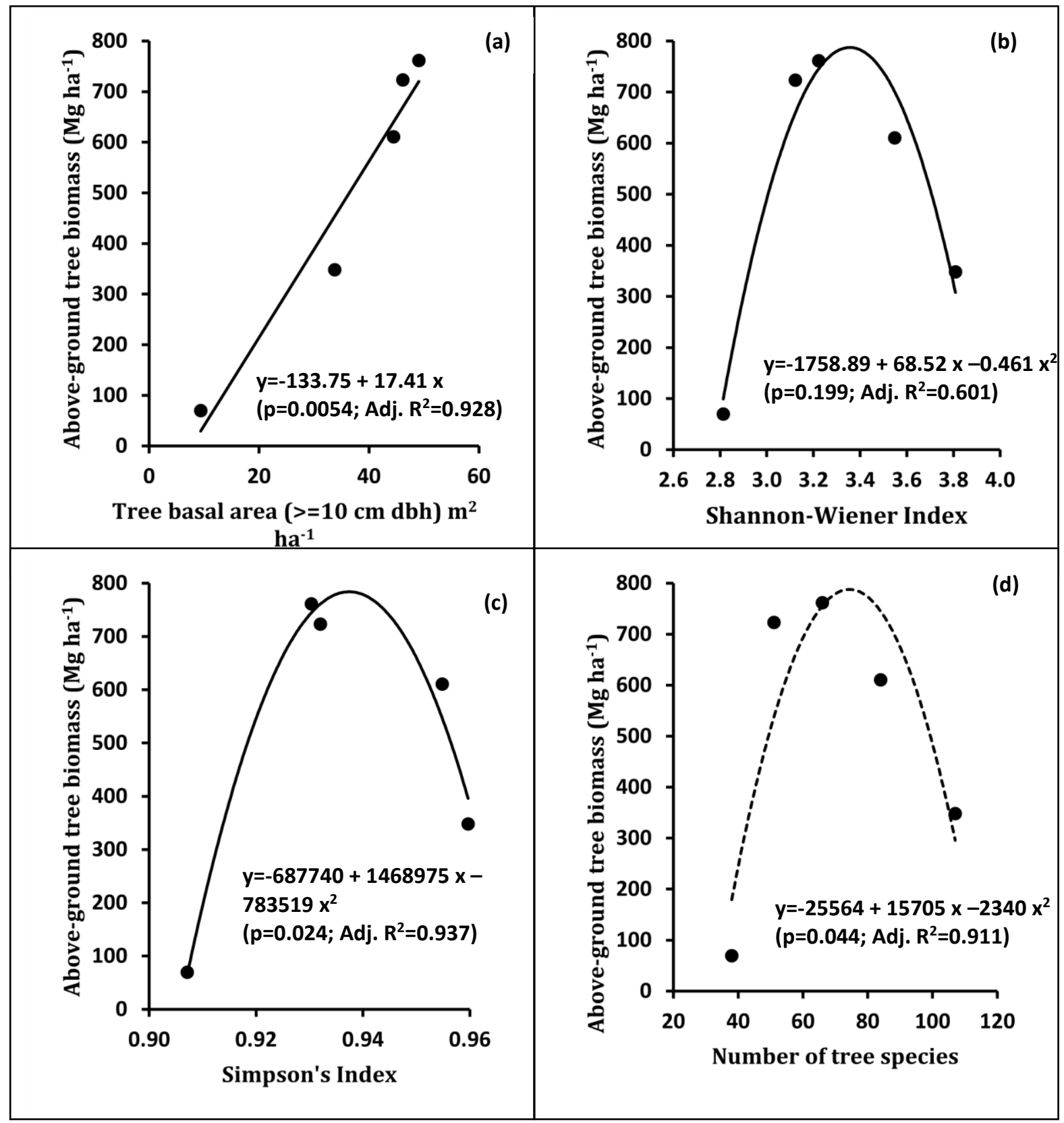

Figure 7: Relationships of aboveground tree biomass with tree basal area (a), ShannonWiener Index (b), Simpson's Index (c) and number of tree species (d).

The observed trends of tree density, floristic composition and tree diversity of Sri Lankan
TRFs with altitude is probably caused by the combined variation of several climatic and 
edaphic factors that vary with altitude. Among the climatic factors, temperature variation with altitude is widely recognized as a major determinant of the observed variation in vegetation (Malhi et al., 2010; Slik et al., 2010; Marshall et al., 2012). In addition, edaphic variations in the underlying geology, soil depth and physical properties and soil chemical properties could also be significant contributory factors (Raich et al., 1997; Aiba and Kitayama 1999; Kitayamat and Aiba 2002; Marshall et al., 2012). However, the present study has confined itself to an initial identification of the response patterns across the altitudinal gradient. Explanation of the observed trends in terms of environmental variables requires a comprehensive presentation of climatic and soil variations in the sampling plots, which is beyond the scope of this paper.

\section{CONCLUSIONS}

Initial findings of this study, which is part of a more extensive and longer-term study, provide indicators to the direction and pattern of variation of the floristic composition, tree diversity and aboveground biomass with altitude in the tropical rainforests in Sri Lanka. These findings point towards decreasing trends in tree density, numbers of species, genera and families and therefore decreasing tree species diversity with increasing altitude. On the other hand, observed trends in tree basal area and total aboveground biomass indicate a curvilinear trend, with increases up to a mid-altitude ca. $600-700 \mathrm{~m}$ asl, followed by decreases.

Interestingly, tree diversity-aboveground biomass relationship also shows a similar pattern indicating a peak in biomass at intermediate diversity. These trends show both agreement and disagreement with corresponding observations along altitudinal gradients in tropical rainforests in other parts of the world. The present study is being expanded currently by incorporating more sampling plots across a wider altitudinal gradient and repeated measurements on a finer scale. A more extensive data set so generated is expected to provide insights into the underlying mechanisms that govern the response of tropical rainforests in Sri Lanka to the altitudinal variation that they are exposed to. Currently, the present study represents the first of its kind on the response of Sri Lankan rainforests to altitudinal gradients.

\section{REFERENCES}

Aiba, S., and Kitayama, K. (1999). Structure Composition and Species Diversity in an Altitude-Substrate Matrix of Rain Forest Tree Communities on Mount Kinabalu , Borneo. Plant Ecology, 140: 139-157.

Baker, T. R., Phillips, O. L., Malhi, Y., Almeida, S., Arroyo, L., Di Fiore, A. and Vásquez Martínez, R. (2004). Increasing biomass in Amazonian forest plots. Philosophical Transactions of the Royal Society B: Biological Sciences, 359(1443): 353-365. https://doi.org/ $10.1098 /$ rstb.2003.1422

Bates, D., Maechler, M., Bolker, B., Walker, S., Christensen, R. H. B., Singmann, H. and Green, P. (2017). Linear Mixed-Effects Models using 'Eigen' and S4. Retrieved from https://github.com/lme4/lme4/ http://lme4.r-forge.r-project.org/

Brienen, R. J. W., Phillips, O. L., Feldpausch, T. R., Gloor, E., Baker, T. R., Lloyd, J. and Zagt, R. J. (2015). Long-term decline of the Amazon carbon sink. Nature, 519(7543):, 344-348. https://doi.org/10.1038/nature14283

Chave, J., Andalo, C., Brown, S., Cairns, M. A., Chambers, J. Q., Eamus, D.and Yamakura, T. (2005). Tree allometry and improved estimation of carbon stocks and balance in 
tropical forests. Oecologia, 145(1): 87-99. https://doi.org/10.1007/s00442-005-0100-x

Chave, Jerome, Coomes, D., Jansen, S., Lewis, S. L., Swenson, N. G. and Zanne, A. E. (2009). Towards a worldwide wood economics spectrum. Ecology Letters, 12(4): 351-366. https://doi.org/10.1111/j.14610248.2009.01285.x

Culmsee, H., Leuschner, C., Moser, G. and Pitopang, R. (2010). Forest aboveground biomass along an elevational transect in Sulawesi, Indonesia, and the role of Fagaceae in tropical montane rain forests. Journal of Biogeography, 1-15. https://doi.org/10.1111 /j.1365-2699.2009.02269.x

Detwiler, R. P. andHal, C. A. S. (1988). Tropical Forests and the Global Carbon Cycle. Science, $239,42-47$.

Fick, S. E. and Hijmans, R. J. (2017). WorldClim 2: new 1-km spatial resolution climate surfaces for global land areas. International Journal of Climatology, 37(12): 4302-4315.

Gallery, R. E. (2014). Ecology of Tropical Rain Forests. In: Ecology and the Environment, Monson (Ed.), Springer, New York, 1-22. https://doi.org/10.1007/978-1-4614-7501-9

Gentry, A. H. (1988). Changes in plant community diversity and floristic composition on environmental and geographic gradients. Annals of the Missouri Botanical Garden, 75(1): 1-34. Retrieved from http://www.jstor.org/ stable/2399464.

Girardin, C. A. J., Malhi, Y., Aragão, L. E. O. C., Mamani, M., Huaraca Huasco, W., Durand, L., Whittaker, R. J. (2010). Net primary productivity allocation and cycling of carbon along a tropical forest elevational transect in the Peruvian Andes. Global Change Biology, 16: 3176-3192. https://doi.org/10.1111/j.1365- 2486.2010.02235.x

Givnish, T. J. (1999). On the causes of gradients in tropical tree diversity. Journal of Ecology, 87: 193-210.

Gould, W. A., González, G. and Carrero Rivera, G. (2006). Structure and composition of vegetation along an elevational gradient in Puerto Rico. Journal of Vegetation Science, 17: 653-664. https://doi.org/10.1111/j.16541103.2006.tb02489.x

Gunawardene, N. R., Dulip Daniels, A. E., Gunatilleke, I. A. U. N., Gunatilleke, C. V. S., Karunakaran, P. V., Geetha Nayak, K. and Vasanthy, G. (2007). A brief overview of the Western Ghats - Sri Lanka biodiversity hotspot. Current Science, 93(11): 1567-1572.

Harja, D., Rahayu, S. and Pambudi, S. (2019). Tree functional attributes and ecological database. Retrieved from http:// db.worldagroforestry.org/

Homeier, J., Breckle, S., Günter, S., Rollenbeck, R. T., Homeier, J., Breckle, S. and Leuschner, C. (2010). Tree Diversity , Forest Structure and Productivity along Altitudinal and Topographical Gradients in a Species-Rich Ecuadorian Montane Rain Forest. Biotropica, 42(2): 140-148. https://doi.org/10.1111 /j.1744-7429.2009.00547.x

Kindt, R. and Coe, R. (2005). Tree diversity analysis: a manual and software for common statistical methods for ecological and biodiversity studies. Retrieved from http://www.worldagroforestry.org/output/t ree-diversity-analysis

Kitayama, K. and Aiba, S. I. (2002). Ecosystem structure and productivity of tropical rain forests along altitudinal gradients with contrasting soil phosphorus pools on Mount Kinabalu,Borneo. Journal of Ecology, 90(1): 
37-51. https://doi.org/10.1046/j.0022-0477. 2001.00634.x

Kitayamat, K. and Aiba, S. (2002). Ecosystem structure and productivity of tropical rainforests along altitudinal gradients with contrasting soil phosphoruspools on Mount Kinabalu, Borneo. Journal of Ecology, 90: 3751.

Körner, C. (2007). The use of 'altitude' in ecological research. Trends in Ecology and Evolution, 22(11): 569-574. https://doi.org/ 10.1016/j.tree.2007.09.006

Leuschner, C. and Moser, G. (2008). Carbon allocation and productivity in tropical mountain forests. In D. G. S. Robbert Gradstein, Jürgen Homeier (Ed.), Biodiversity and Ecology Series (Vol. 2, pp. 109-128).

Lieberman, D., Lieberman, M., Peralta, R. and Hartshorn, G. S. (1996). Tropical Forest Structure and Composition on a Large-Scale Altitudinal Gradient in Costa Rica. Journal of Ecology, 84: 137-152. https://doi.org/10. $2307 / 2261350$

Lovett, J. C., Marshall, A. R. and Carr, J. (2006). Changes in tropical forest vegetation along an altitudinal gradient in the Udzungwa Mountains National Park, Tanzania. African Journal of Ecology, 44(4): 478-490. https://doi.org/10.1111/j.1365-2028.2006. 00660.x

Malhi, Y., Girardin, C. A. J., Goldsmith, G. R., Doughty, C. E., Salinas, N., Metcalfe, D. B. and Silman, M. (2017). The variation of productivity and its allocation along a tropical elevation gradient: a whole carbon budget perspective. New Phytologist, 214: 1019-1032. https://doi.org/10.1111/nph.14189

Malhi, Y., Silman, M., Salinas, N., Bush, M., Meir, P. and Saatchi, S. (2010). Introduction:
Elevation gradients in the tropics: Laboratories for ecosystem ecology and global change research. Global Change Biology, 16(12): 3171-3175. https://doi.org/10.1111 /j.1365-2486.2010.02323.x

Marshall, A. R., Willcock, S., Platts, P. J., Lovett, J. C., Balmford, A., Burgess, N. D. and Lewis, S. L. (2012). Measuring and modelling aboveground carbon and tree allometry along a tropical elevation gradient. Biological Conservation, 154: 20-33. https://doi.org/ 10.1016/j.biocon.2012.03.017

Moser, G., Leuschner, C., Hertel, D., Graefe, S., Soethe, N. and Iost, S. (2011). Elevation effects on the carbon budget of tropical mountain forests (S Ecuador): The role of the belowground compartment. Global Change Biology, 17(6): 2211-2226. https://doi.org/ 10.1111/j.1365-2486.2010.02367.x

Oksanen, J., Blanchet, F. G., Kindt, R., Endre, P. L.-, Minchin, P. R., O'Hara, R. B. and Wagner, H. (2019). Community Ecological package.

Phillips, O. L., Malhi, Y., Higuchi, N., Laurance, W. F., Nu, P. V, Laurance, S. G. and Grace, J. (1998). Changes in the Carbon Balance of Tropical Forests : Evidence from Long-Term Plots. Science, 282(OCTOBER): 439-442.

Raich, J. W., Russell, A. E. and Vitousek, P. M. (1997). Primary Productivity and Ecosystem Development Along an Elevational Gradient on Mauna Loa , Hawaii. Ecology, 78(3): 707721. https://doi.org/10.2307/2266051

Reyes, G., Brown, S., Jonathan Chapman and Lugo, A. E. (1992). Wood Densities of Tropical Tree Species. New Orleans, LA: U.S.

Slik, J. W. F., Aiba, S. I., Brearley, F. Q., Cannon, C. H., Forshed, O., Kitayama, K. and van Valkenburg, J. L. C. H. (2010). Environmental correlates of tree biomass, basal area, wood 
specific gravity and stem density gradients in Borneo's tropical forests. Global Ecology and Biogeography, 19, 50-60. https://doi.org/ 10.1111/j.1466-8238.2009.00489.x

Sullivan, M. J. P., Talbot, J., Lewis, S. L., Phillips, O. L., Qie, L., Begne, S. K. and Zemagho, L. (2017). Diversity and carbon storage across the tropical forest biome. Scientific Reports, 7(39102), 1-12. https://doi.org/ 10.1038/ srep39102

Vázquez G., J. A. and Givnish, T. J. (1998). Altitudinal gradients in tropical forest composition, structure, and diversity in the Sierra de Manantlan. Journal of Ecology, 86(6), 999-1020. https://doi.org/10.1046/j.13652745.1998.00325.x
Wang, H., Hall, C. A. S., Scatena, F. N., Fetcher, N. and Wu, W. (2003). Modeling the spatial and temporal variability in climate and primary productivity across the Luquillo Mountains, Puerto Rico. Forest Ecology and Management, 179(1-3): 69-94. https://doi.org/ 10.1016/ S0378-1127(02)00489-9

Weaver, P. L. and Murphy, P. G. (1990). Forest Structure and Productivity in Puerto Rico ' s Luquillo Mountains. Biotropica, 22(1), 69-82.

Zanne, A. E., Lopez-Gonzalez, G., Coomes, D. A., Ilic, J., Jansen, S., Lewis, S. L. and Chave, J. (2009). Data from: Towards a worldwide wood economics spectrum. Retrieved from https://datadryad.org/resource/doi:10.5061 /dryad.234 